\title{
Xenogenic demineralized bone matrix and fresh autogenous cortical bone effects on experimental bone healing: radiological, histopathological and biomechanical evaluation
}

\author{
A. S. Bigham $\cdot$ S. N. Dehghani $\cdot$ Z. Shafiei $\cdot$ \\ S. Torabi Nezhad
}

Received: 4 February 2008/Accepted: 7 April 2008/Published online: 10 May 2008

(C) Springer-Verlag 2008

\begin{abstract}
Background Bone grafting is used to enhance healing in osteotomies, arthrodesis, and multifragmentary fractures and to replace bony loss resulting from neoplasia or cysts. They are source of osteoprogenitor cells and induce bone formation and provide mechanical support for vascular and bone ingrowth. Autografts are used commonly but quantity of harvested bone is limited. The aim of this study is to evaluate autograft and new xenogenic bovine demineralized bone matrix (DBM) effects on bone healing process. Materials and methods Twenty male White New Zealand rabbits were used in this study. In group I $(n=10)$ the defect was filled by xenogenic DBM and in autograft group the defect was filled by fresh autogenous cortical graft and fixed by cercelage wire. Radiological, histopathological and biomechanical evaluations were performed blindly and results scored and analyzed statistically.

Results Statistical tests did not reveal any significant differences between two groups on the 14th postoperative day radiographically $(P>0.05)$. There was a significant difference for union on 28th and 42nd postoperative days and for remodeling at on the 56th postoperative day radiologically $(P<0.05)$. Statistical tests did not support
\end{abstract}

\footnotetext{
A. S. Bigham $(\square)$

Department of Veterinary Surgery and Radiology,

Faculty of Veterinary Medicine, Shahrekord University,

P. O. Box: 115, Shahrekord, Iran

e-mail: dr.bigham@gmail.com

S. N. Dehghani · Z. Shafiei

Department of Surgery, School of Veterinary Medicine,

Shiraz University, Shiraz, Iran

S. Torabi Nezhad

College of Medicine, University of Medical Science, Shiraz, Iran
}

any significant differences between two groups for radiological bone formation $(P>0.05)$. Histopathological and biomechanical evaluation revealed no significant differences between two groups.

Conclusions The results of this study indicate that satisfactory healing occurred in rabbit radius defect filled with xenogenic bovine DBM. Complications were not identified and healing was faster, same as in cortical autogenous grafting.

Keywords Xenogenic DBM - Autogenous cortical bone . Bone healing · Rabbit

\section{Introduction}

Bone grafting is used to enhance healing in delayed unions, nonunions, ostoectomies, arthrodesis, multifragmentary fractures and to replace bony loss resulting from neoplasia or cysts [1]. Autogenous bone graft is commonly used and is the standard to which allografts and graft substitutes are compared [2-7]. They may provide a source of osteoprogenitor cells (osteogenesis), induce formation of osteoprogenitor cells from surrounding tissues (osteoinduction), and provide mechanical support for vascular and bone ingrowth (osteoconduction) [8]. Though autogenous bone grafts have been clinically effective, the additional surgical time required to harvest an autogenous graft, the morbidity associated with its collection, and the limited availability of autogenous bone in some patients, have encouraged the search of suitable bone graft substitutes [5, 9-11]. Therefore, the use of various bone graft substitutes including autografts, allografts, xenografts, polymers, ceramics and some metals have been employed to promote bone reunion $[12,13]$. 
Allogenic, demineralized bone matrix (DBM) has been used for several decades in human surgery for the treatment of nonunions, osteomyelitis and large defects resulting from benign tumor removal [14]. The process of demineralization with hydrochloric acid destroys, but also decreases antigenic stimulation and may enhance the release of bone morphogenic protein (BMP) [15]. BMPs stimulate local undifferentiated mesenchymal cells to transform into osteoblasts (osteoinduction), and the collagenous framework of the DBM particles allows for migration of tissue into the site (osteoconduction). Extensive research continues to identify the different BMPs that might be osteoinductive, and these are being readied for clinical application [16-19]. Beyond their role in osteoinduction, certain BMPs and DBM have shown promise in aiding repair of osteochondral defects [20,21]. Advantages of DBM over other substitutes include inherent osteoinductive capacity (unlike tricalcium phosphate and hydroxyapatite) and availability in large amounts. The aim of study reported here was to compare the effects of xenogenic bovine DBM and fresh cortical autogenous bone on the healing of bone defects in rabbits.

\section{Materials and methods}

\section{Animals}

Twenty male New Zealand Albino rabbits 12 months old and weighing $3.0 \pm 0.5 \mathrm{~kg}$ were used in this study. The research protocol for this experiment was approved by the Shiraz University research committee.

Preparation of bovine demineralized bone matrix

Demineralized bone matrix, prepared from the midshafts of the long bones of a 2-year-old Holstein cow, were collected from the local slaughterhouse. All bones were collected aseptically, and the soft tissues were removed before storage at $-70^{\circ} \mathrm{C}$. The bones were later cleared of fascia and cut into $1-\mathrm{cm}$ pieces with a Stryker saw under saline $(0.9 \% \mathrm{NaCl})$ solution lavage. Bone pieces were stored at $-70^{\circ} \mathrm{C}$ until further use. The pieces were then thawed in 200-proof ethanol and air-dried. All bones were milled (Universal Mill A-20; Tekmer Co, Cincinnati, OH, USA) and placed through a sieve to collect 2- to 4-mm pieces. The pieces were then decalcified in $0.6 \mathrm{~mol} / \mathrm{l} \mathrm{HCL}$ at $4^{\circ} \mathrm{C}$ for 8 days under constant agitation.

Demineralization was evaluated with radiography and calcium analysis [22]. Density loss of xenogenic demineralized bone matrix was evaluated radiographically. Also, random samples of $\mathrm{DBM}$ were dried at $95^{\circ} \mathrm{C}$, weighed, and then ashed at $600^{\circ} \mathrm{C}$ for $24 \mathrm{~h}$. These samples were then dissolved in $0.6 \mathrm{~mol} / \mathrm{l}$ nitric acid and analyzed by atomic absorption spectrophotometry to determine percent calcium per gram dry weight (\% Ca:DW) [23, 24]. Demineralization was considered adequate when samples were no longer visible radiographically and when calcium content was less than $1 \%$ [25]. After demineralization, all bone pieces were rinsed in sterile water and placed in phosphate buffer overnight. The bone pieces were then rinsed and the $\mathrm{pH}$ was adjusted to 7.3. They were placed in ethanol, the ethanol was allowed to evaporate overnight, and the pieces were packaged aseptically and stored at $4^{\circ} \mathrm{C}$.

Preparation of fresh cortical autogenous bone graft

Fresh autogenous cortical bone was harvested at the time of surgery during the creation of radius bone defect. Then all soft tissues were removed from the harvested bone and used as a fresh autogenous cortical bone graft.

Surgical technique

Animals were anaesthetized with ketamine (40 mg/kg, IM) and xylazine $(5 \mathrm{mg} / \mathrm{kg}$, IM). The left forelimb was shaved and prepared aseptically with povidone iodine and the limb draped with sterile drapes. An incision was made directly over the radius; which was exposed by dissection of surrounding muscles. Then an osteoperiosteal segmental defect was created on the middle portion of each radius at least twice as long as the diameter of the diaphysis for creation of nonunion model [26]. The created defects were filled in ten rabbits (group I) with DBM $(20 \mathrm{mg} / \mathrm{defect})$ and in other ten rabbits (group II) with same harvested segment of cortical bone and fixed by cercelage wire for prevention of segment dislocation in the grafted area.

Postoperative evaluation

\section{Radiological evaluation}

Radiographs of each forelimb were taken postoperatively on 1st day and at the 2nd, 4th, 6th and 8th weeks to evaluate bone formation, union and remodeling of the defect. Results were scored using a modified Lane and Sandhu scoring system [27] (Table 1).

\section{Histopathological evaluation}

Eight weeks after operation the rabbits were euthanized pharmacologically for histopathological and biomechanical evaluation. Histopathological evaluation was carried out on 
Table 1 Modified Lane and Sandhu radiological scoring system

Bone formation

No evidence of bone formation

Bone formation occupying $25 \%$ of defect

Bone formation occupying $50 \%$ of defect

Bone formation occupying $75 \%$ of defect

Bone formation occupying $100 \%$ of defect

Union (proximal and distal evaluated separately)

Nonunion

Possible union

Radiographic union

Total point possible per category

Bone formation

Proximal union

Distal union

Remodeling

Maximum Score

five rabbits of each group randomly. Left forelimb were harvested and dissected free of soft tissues. Sagittal sections that contained the defect site were cut with a slow-speed saw. Each slice was then fixed in $10 \%$ formalin. The formalin-fixed bone samples were decalcified in $15 \%$ buffered formic acid solution and processed for routine histological examination. Two 5-micron thick sections were cut from the centers of each specimen and were stained with hematoxylin and eosin. The sections were individually evaluated and scored by pathologist blinded to the treatment. Scoring system was according to lane and Sandhu modified scoring system by Hieple et al 1987 (Table 2) [28].

\section{Biomechanical evaluation}

Mechanical bending test was performed on radial-healed defect of the left forelimb of five rabbits of each group by biomechanical testing machine (Shimatzo, Japan). During the test, the bone ends were placed between two jaws in the testing machine and the load exerted at the grafting area until the failure. The forces, which were needed to break the bones were recorded. Data derived from mechanical testing were expressed as the mean \pm SEM (standard error mean) for each group.

\section{Statistical analysis}

The radiological and histopathological data were compared by Kruskal-Wallis, non-parametric ANOVA, when $P$-values were found to be less than 0.05 , then pair wise group comparisons were performed by Mann-Whitney $U$ test. The biomechanical data was compared by a Student's $t$-test (SPSS 15.00).
Table 2 Lane and Sandhu histopathological scoring system modified by Heiple et al. [28]

Union (proximal and distal evaluated separately)

No evidence of union $\quad 0$

Fibrous union 1

Osteochondral union $\quad 2$

Bone union 3

Complete organization of shaft 4

Cancellous bone

No osseous cellular activity 0

Early apposition of new bone 1

Active apposition of new bone 2

Reorganizing cancellous bone 3

Complete reorganization of cancellous bone 4

Cortical bone

Non 0

Early appearance 1

Formation under way 2

Mostly reorganized 2

$\begin{array}{ll}\text { Completely formed } & 10\end{array}$

Marrow

None is resected area $\quad 0$

Beginning to appear 1

Present in more than half of the defect 2

Complete colonization by red marrow 3

Mature fatty marrow 4

Total points possible per category

Proximal union 4

Distal union 4

Cancellous bone $\quad 4$

Cortex 4

Marrow 4

Maximum score $\quad 20$

\section{Results}

There was no intraoperative and postoperative death during the study. None of the rabbits sustained a fracture of the radius.

\section{Radiographic findings}

There was $25 \%$ bone formation in some rabbits in group I and group II on 14th postoperative day. Although there was union in some rabbits of group I, there was no evidence of union in group II. Remodeling was not found in either group. Statistical tests did not support any significant difference (Table 3, $P>0.05$ ) (Fig. 1).

There was $50-75 \%$ bone formation in some rabbits of group I and 0-25\% bone formation in some rabbits of group II on 28th postoperative day. Although there was some union 
Table 3 Radiological findings at 2 nd week

\section{${ }^{a}$ Kruskal-Wallis non- parametric ANOVA}

Fig. 1 Radiographs of forelimb on 14 th postoperative day. (a Xenogenic DBM. b autograft)

\begin{tabular}{llll}
\hline & \multicolumn{2}{l}{ Median (min-max) } & $P^{\mathrm{a}}$ \\
\cline { 2 - 4 } & Group I $(n=10)$ & Group II $(n=10)$ & \\
\hline Bone formation & $0(0-0)$ & $0(0-1)$ & 0.11 \\
Proximal union & $0(0-0)$ & $0(0-1)$ & 0.36 \\
Distal union & $0(0-0)$ & $0(0-0)$ & 1.000 \\
Remodeling & $0(0-0)$ & $0(0-0)$ & 1.000 \\
\hline
\end{tabular}
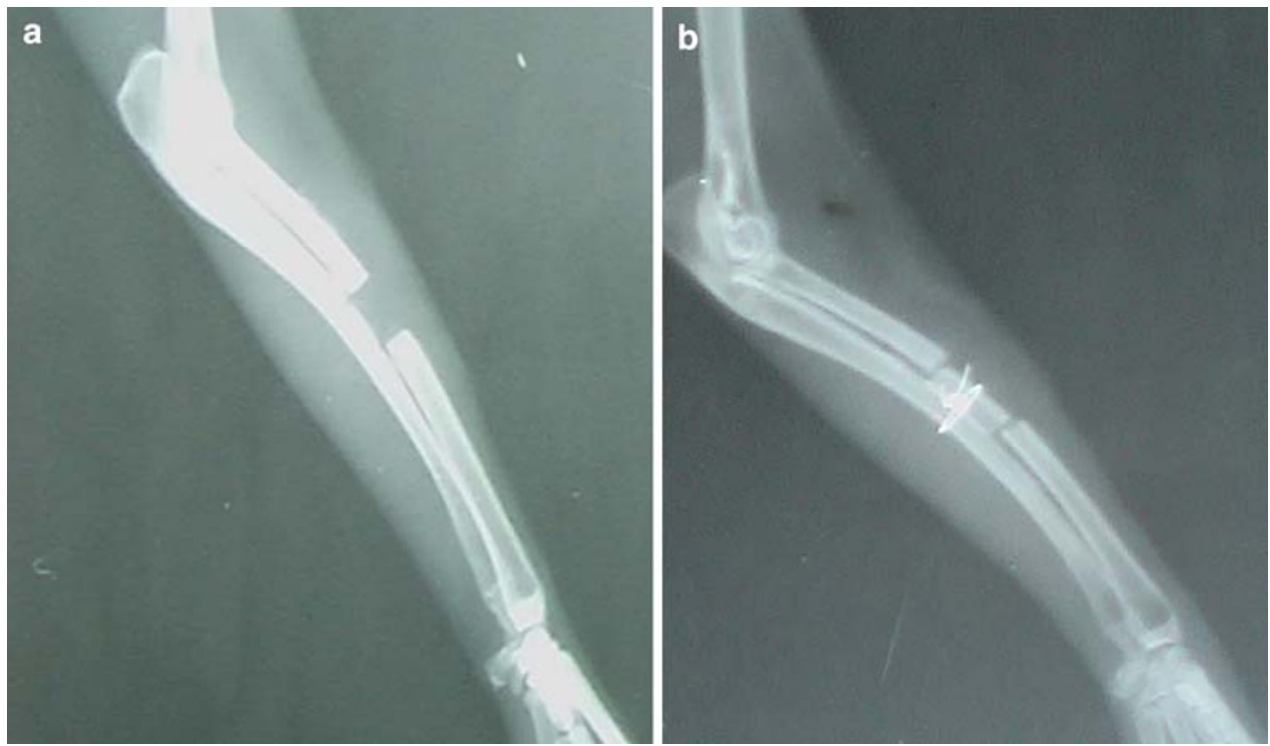

in most rabbits of group II, remodeling was not seen in all rabbits of either groups. There was a statistically significant difference only for union at the 28th postoperative day in the radiological signs of bone healing $(P<0.05)$. When pairwise group comparisons were performed by Mann-Whitney $U$ test, group II was found to be superior to group I (Table 4, $P=0.008$ and $P=0.03$ ) (Fig. 2).

There was $75-100 \%$ bone formation in all rabbits in group I and 50-75\% bone formation in all rabbits of group II on 42 nd postoperative day. Although there was some union in all rabbits of both groups and some remodeling in group I. There was a statistically significant difference only for union at the 42 nd postoperative day in the radiological

Table 4 Radiological findings at 4th week

\begin{tabular}{llll}
\hline & \multicolumn{2}{l}{ Median (min-max) } & $P^{\mathrm{a}}$ \\
\cline { 2 - 3 } & Group I $(n=10)$ & Group II $(n=10)$ & \\
\hline Bone formation & $1(1-1)$ & $1(1-1)$ & 0.006 \\
Proximal union & $0(0-0)$ & $1(1-1)^{\mathrm{b}}$ & $\mathbf{0 . 0 0 4}$ \\
Distal union & $0(0-0)$ & $1(0-1)^{\mathrm{c}}$ & $\mathbf{0 . 0 0 6}$ \\
Remodeling & $0(0-0)$ & $0(0-0)$ & 1.000 \\
\hline
\end{tabular}

Significant $P$-values are presented in bold face

${ }^{a}$ Kruskal-Wallis non-parametric ANOVA

b $P=0.008$ (compared with group I by Mann-Whitney $U$ test)

${ }^{\text {c }} P=0.03$ (compared with group I by Mann-Whitney $U$ test) signs of bone healing $(P<0.05)$. When pairwise group comparisons were performed by Mann-Whitney $U$ test, group II was found to be superior to group I (Table 5, $P=0.01$ ) (Fig. 3).

There was $100 \%$ bone formation and union in group I and $75-100 \%$ bone formation and some union in group II on 56th postoperative day. There were $25-50 \%$ points remodeling in the two groups. Group II was statistically superior to group I only in terms of radiological callus remodeling $(P<0.05)$. When pairwise group comparisons were performed with Mann-Whitney $U$ test, the group II was superior to group I (Table 6, $P<0.03$ ) (Fig. 4).

\section{Histopathological findings}

Histopathologically there was no statistically significant difference between the groups in terms of cancellous and cortical bone, union and marrow formation. None of the grafted materials elicited a significant inflammatory reaction. In the group II the chondroblastic differentiation zone was observed (Table 7, $P>0.05$ ) (Fig. 5).

\section{Biomechanical findings}

There was no statistically significant difference between two groups in terms of biomechanical bending test (Table $8, P>0.05$ ). 
Fig. 2 Radiographs of forelimb on 28th postoperative day.

(a Xenogenic DBM,

b autograft)
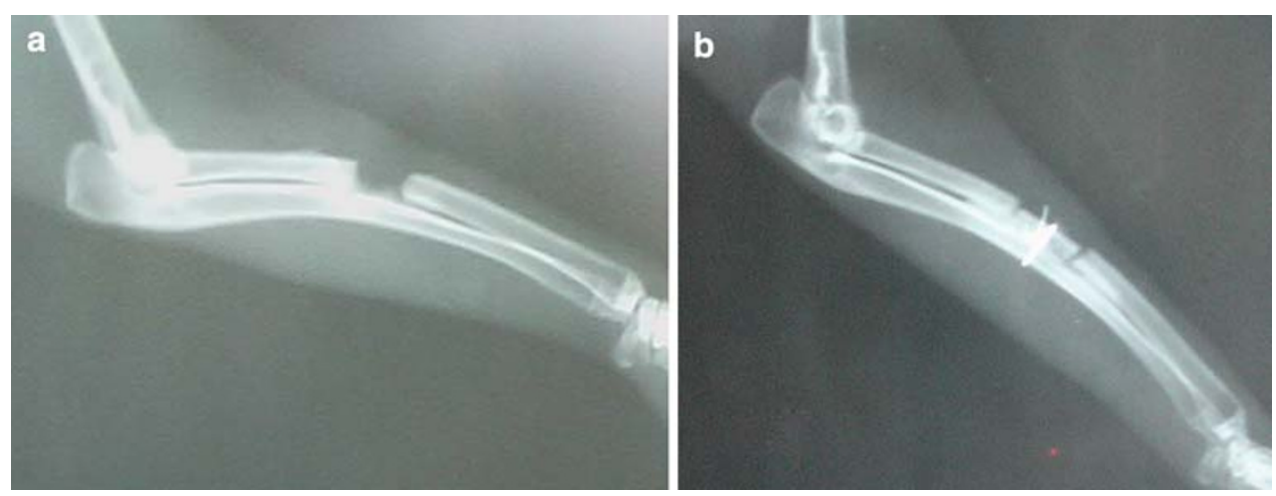

Table 5 Radiological findings at 6 th week

\begin{tabular}{llll}
\hline & \multicolumn{2}{l}{ Median (min-max) } & $P^{\mathrm{a}}$ \\
\cline { 2 - 3 } & Group I $(n=10)$ & Group II $(n=10)$ & 0.11 \\
\hline Bone formation & $2(1-3)$ & $2(1-2)$ & $\mathbf{0 . 0 0 8}$ \\
Proximal union & $1(0-1)$ & $2(1-2)^{\mathrm{b}}$ & 0.01 \\
Distal union & $1(0-1)$ & $2(1-2)$ & 0.17 \\
Remodeling & $1(0-1)$ & $1(0-1)$ & \\
\hline
\end{tabular}

Significant $P$ values are presented in bold face

${ }^{a}$ Kruskal-Wallis non-parametric ANOVA

${ }^{\text {b }} P=0.01$ (compared with group I by Mann-Whitney $U$ test)

Fig. 3 Radiographs of forelimb on 42 nd postoperative day.

(a Xenogenic DBM,

b autograft)
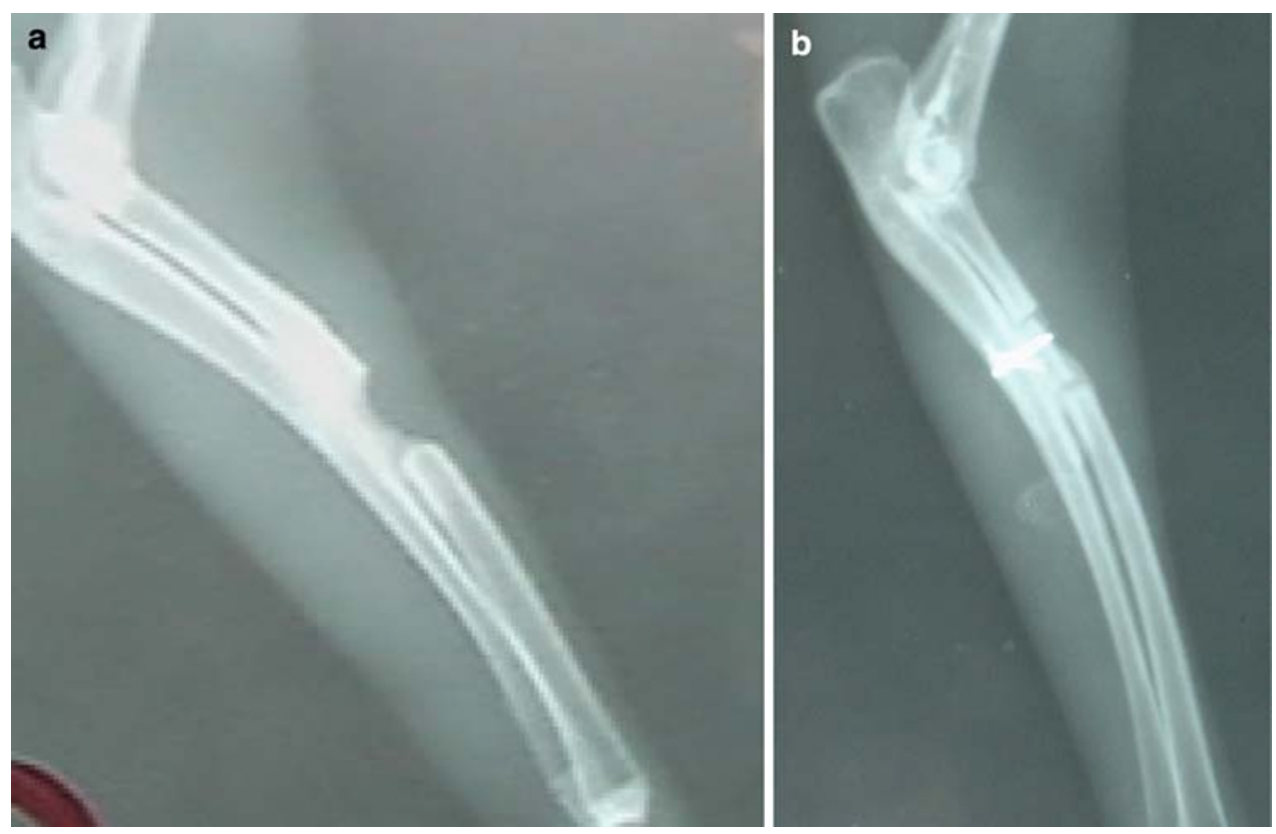

\section{Discussion}

In this study a radius defect model was created to compare healing of bovine DBM implant as a new xenograft and fresh autogenous cortical bone graft in the rabbit model. This model has been reported previously suitable because there was no need for internal or external fixation that can influence the healing process [29]. The osteoperiosteal segemental defect was created in middle portion of radius at least twice as long as the diameter of diaphysis to produce nonunion model and prevent spontaneous healing [26]. 
Table 6 Radiological findings at 8th week

\begin{tabular}{llll}
\hline & \multicolumn{2}{c}{ Median $(\min -\mathrm{max})$} & $P^{\mathrm{a}}$ \\
\cline { 2 - 3 } & Group I $(n=10)$ & Group II $(n=10)$ & 0.13 \\
\hline Bone formation & $2(0-3)$ & $2(1-3)$ & 0.9 \\
Proximal union & $1(0-2)$ & $2(1-2)$ & 0.1 \\
Distal union & $1(0-2)$ & $1(1-2)$ & $\mathbf{0 . 0 0 7}$ \\
Remodeling & $1(1-1)$ & $1(0-2)^{\mathrm{b}}$ & \\
\hline
\end{tabular}

Significant $P$-values are presented in bold face

a Kruskal-Wallis non-parametric ANOVA

${ }^{\text {b }} P=0.03$ (compared with group I by Mann-Whitney $U$ test)

Fig. 4 Radiographs of forelimb on 56th postoperative day.

(a Xenogenic DBM,

b autograft)
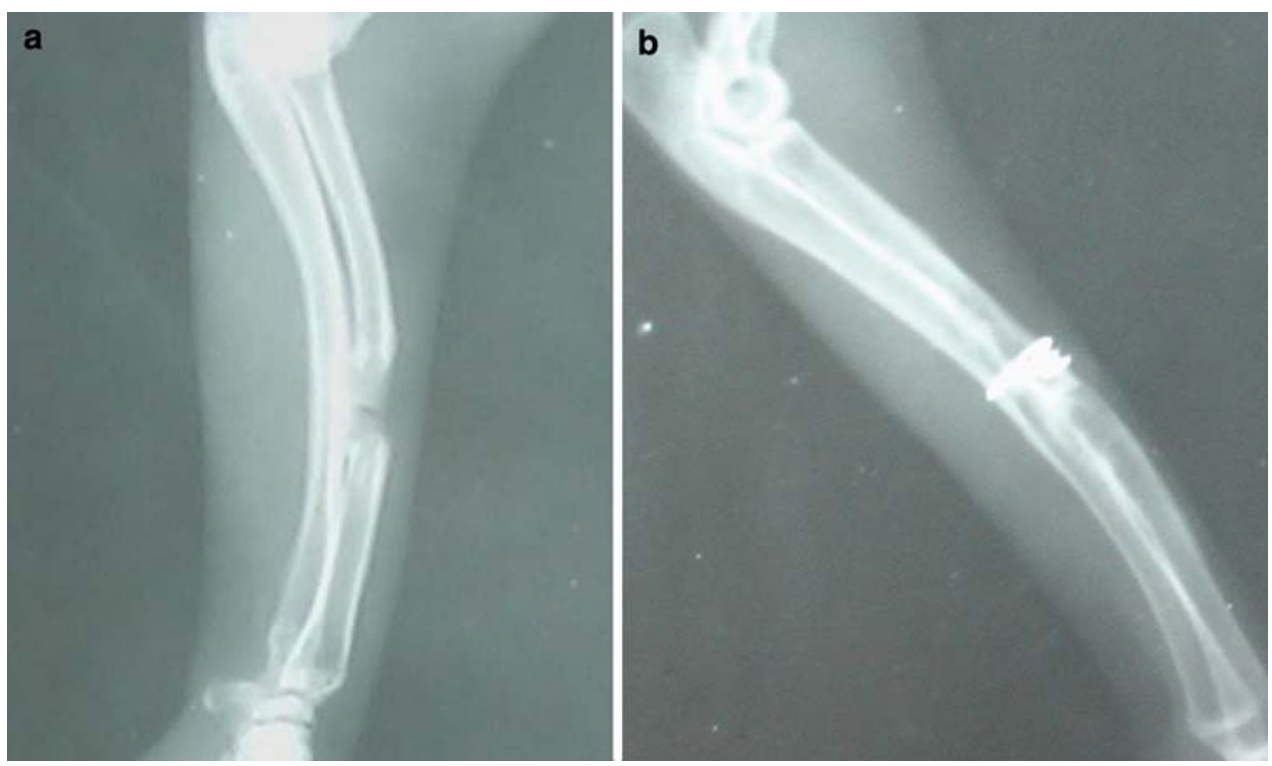

Table 7 Histopathological findings at 8th week

${ }^{a}$ Kruskal-Wallis nonparametric ANOVA

Fig. 5 Histopathological evaluation of a Xenogenic DBM implantation. Note the chondroblastic differentiation in grafted area (white arrow) $(H \& E \times 100)$ and $\mathbf{b}$ cortical bone autograft

\begin{tabular}{llll}
\hline & \multicolumn{2}{l}{ Median (min-max) } & $P^{\mathrm{a}}$ \\
\cline { 2 - 4 } & Group I $(n=5)$ & Group II $(n=5)$ & \\
\hline Union & $2(1-2)$ & $1(1-2)$ & 0.2 \\
Cortical bone & $1(0-3)$ & $1(0-2)$ & 0.9 \\
Cancellous bone & $1(1-3)$ & $1(0-3)$ & 0.6 \\
Bone marrow & $1(0-2)$ & $1(0-2)$ & 1.000 \\
\hline
\end{tabular}
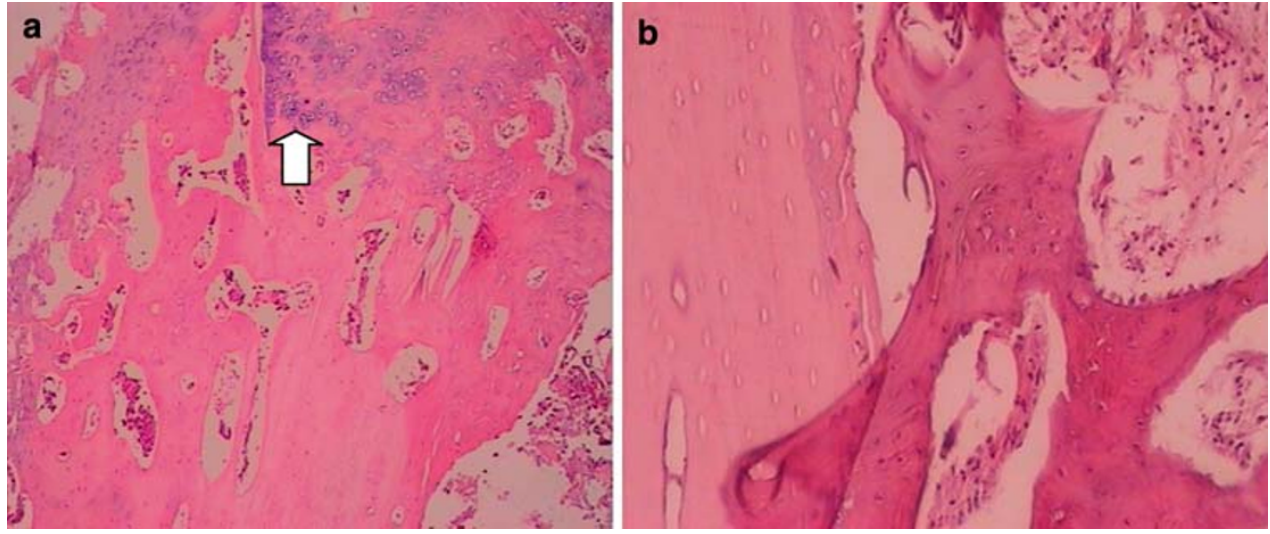
Table 8 Biomechanical three point bending test findings (mean \pm SEM)

\begin{tabular}{llll}
\hline Group & I & II & $P$ value \\
\hline Maximum load (kgf) & $9.04 \pm 0.97$ & $6.9 \pm 0.56$ & 0.09 \\
\hline
\end{tabular}

$S E M$ standard error mean

The bone inductive activity of DBM has been wellestablished [30-38]. The addition of autologous bone marrow and/or autograft to DBM provides an immediate source of osteogenic precursor cells at the implant site that may provide an additional biochemical contribution to osteogenesis [37-39]. DBM also appears to support new bone formation through osteoconductive mechanisms [40]. Autogenous bone graft is commonly used and is the standard, to which allografts and graft substitute are compared [2-7]. The primary osteoinductive component of DBM is a series of low-molecular-weight glycoproteins that includes the BMPs. The decalcification of cortical bone exposes these osteoinductive growth factors buried within the mineralized matrix, thereby enhancing the bone formation process [41]. These proteins promote the chondroblastic differentiation of mesenchymal cells, followed with new bone synthesis by endochondral osteogenesis [41, 42]. In this study, it was found that the results of group I was not statistically significant after the 8 weeks in comparison with group II. It proves that the grafted xenogenic bovine DBM has osteoinductive (by releasing the some BMPs) activity same as autogenous cortical bone graft. However it was found that cortical autograft has more osteoconductive properties and less osteoinductive activity [43, 44]. DBM also appears to support new bone formation through osteoconductive mechanisms [40]. There were not any significant differences in histopathological evaluation between two groups and none of the graft material elicited a significant inflammatory reaction. It has been reported that the demineralization process destroys the antigenic materials in bone, making DBM less immunogenic than mineralized allograft [45] and the cortical autogenous bone graft does not induce immunological reaction by the host [43]. Therefore, we did not observe any inflammatory reaction in group I and group II. We observed chondroblastic differentiation zone in histopathological evaluation of group I. Urist showed chondroblastic differentiation from mesenchymal cell by bone morphogenetic proteins $[41,42]$. It was understood that the chondroblastic differentiation in group I was related to BMPs releasing from grafted bovine DMB.

In biomechanical evaluation, group I was superior to group II, but there is not any statistically significant difference between two groups. It has been reported that cortical autogenous bone graft remains a combination of necrotic and new bone for a prolonged period and leads to reduction in mechanical strength [46]. Moreover, experimental studies have shown that osteoinductive bone protein growth factors combined with DBM produce biomechanically enhanced fusions as compared to autograft alone [47-50]. A number of well-controlled studies in a wellestablished and validated animal model of posterolateral spine fusion have demonstrated the suitability of various forms of DBM as a graft extender and, in some cases, as a graft enhancer and a graft substitute [40,51]. The results of this study indicate that satisfactory healing occurred in rabbit radius defect filled with xenogenic bovine DBM. Complications were not identified and healing was faster, same as in cortical autogenous grafting. The use of xenogenic bovine DBM is an acceptable alternative to cortical autogenous graft and could reduce the morbidity associated with harvesting autogenous graft during surgery. Further studies are needed to evaluate the long-term effects of DBM implantation on bone healing to document the use of this graft substitute in various clinical situations. DBM has a number of additional advantages that make it an attractive bone graft alternative. It is cost-effective and is readily available from tissue banks.

Conflict of interest statement The authors declare that they have no conflict of interest related to the publication of this manuscript.

\section{References}

1. Van heest A, Swiontkowski M (1999) Bone-graft substitutes. Lancet 353:28-29

2. Alexander JW (1985) Leonard's orthopedic surgery of the dog and cat. WB Saunders Company, Gainesville

3. Alexander JW (1987) Bone grafting. Vet Clin North Am Small Anim Pract 17:811-819

4. Brinker WO, Piermattei DL, Flo GL (1997) Bone grafting. Small animal orthopedics and fracture repair. WB Saunders Company, Gainesville, pp 147-153

5. Fitch R, Kerwin S, Newman-Gage H, Sinibaldi KR (1997) Bone autografts and allografts in dogs. Compend Vet Contin Educ 19:558-575

6. Fox SM (1984) Cancellous bone grafting in the dog: an overview. J Am Anim Hosp Assoc 20:840-848

7. McLaughlin RM, Roush JK (1998) Autogenous cancellous and cortico-cancellous bone grafting. Vet Med 93:1071-1074

8. Albrek T, Johansson C (2001) Osteoinduction, osteoconduction and osteointegration. Eur Spine J 10:S96-S101

9. Griffon DJ, McLaughlin RM, Hoskinson JJ (1996) Effects of a bone-inducing agent derived from a cultured human osteosarcoma cell line after orthopedic and heterotopic implantation in the dog. Vet Comp Orthop traumatol 9:22-28

10. Oonishi H, Kushitani S, Yasukawa E, Kawakami H, Nakata A, Koh S, Hench LL, Wilson J, Tsuji E, Sugihara T (1997) Particulate bioglass compared with hydroxyapatite as a bone graft substitute. Clin Orthop Relat Res 334:316-325

11. Trevor PB, Stevenson S, Carrig CB, Waldron DR, Smith MM (1992) Evaluation of biocompatible osteoconductive polymer as 
an orthopedic implant in dogs. J Am Vet Med Assoc 200:16511660

12. Friedlaender GE (1987) Bone grafts: the basic science rationale for clinical applications. J Bone Joint Surg Am 69:786-790

13. Inoue K, Ohgushi H, Yoshikawa T, Okumura M, Sempuku T, Tamai S, Dohi Y (1997) The effect of aging on bone formation in porous hydroxyapatite: biochemical and histologic analysis. J Bone Miner Res 12:989-994

14. Jin DD (1991) Bone matrix gelatin. Clinical application in 38 cases. Chung-Hua Wai Ko Tsa Chih 29:312-314

15. Riley EH, Lane JM, Urist MR, Lyons KM, Lieberman JR (1996) Bone morphogenetic protein-2: biology and applications. Clin Orthop Relat Res 324:39-46

16. Bostrom MPG, Lane JM, Berberian WS, Missri AAE, Tomin E, Weiland A, Doty SB, Glaser D, Rosen VM (1995) Immunolocalization and expression of bone morphogenic proteins 2 and 4 in fracture healing. J Orthop Res 13:357-367

17. Cook SD, Baffes GC, Wolfe MW, Sampath TK, Rueger DC (1994) Recombinant human bone morphogenetic protein-7 induces healing in a canine long-bone segmental bone defects. J Bone Joint Surg Am 76:827-838

18. Kirker-Head AC (1995) Recombinant bone morphogenic protein: novel substances for enhancing bone healing. Vet Surg 24:408 419

19. Reddi AH (1995) Bone morphogenetic proteins, bone marrow stromal cells, and mesenchymal stem cells. Clin Orthop Relat Res 313:115-119

20. Loredo GA, MacDonald MH, Benton HP (1995) Regulation of glycosaminoglycan metabolism by bone morphogenetic protein-2 in equine cartilage explant cultures. Am J Vet Res 57:554-559

21. Tanaka T, Fujii K, Ohta M, Soshi S, Kitamura A, Murota K (1995) Use of a guanidine extract of demineralized bone in the treatment of osteochondral defects of articular cartilage. J Orthop Res 13:464-469

22. Vail TB, Trotter GW, Powers BE (1994) Equine demineralized bone matrix: relationship between particle size and osteoinduction. Vet Surg 23:386-395

23. Forell EB, Straw RC, Powers BE, et al (1993) Evaluation of the osteoinductive capacity of canine demineralized bone matrix in heterotopic muscle sites of athymic rats. Vet Comp Orthop Traumatol 6:21-28

24. Reddi AH, Huggins C (1972) Biochemical sequences in the transformation of normal fibroblasts in adolescent rats. Proc Natl Acad Sci USA 69:1601-1605

25. Urist MR, Strakes BS (1970) Bone formation in implants of partially and wholly demineralized bone matrix. Clin Orthop 71:271-278

26. Bolander ME, Galian G (1983) The use of demineralize bone matrix in the repair of segmental defect. J Bone Joint Surg 68A:1264-1274

27. Lane JM, Sandhu HS (1987) Current approach to experimental bone grafting. Orthop Clin North Am 18:213-225

28. Heiple KG, Goldberg VM, Powell AE, Bos GD, Zika JM (1987) Biology of cancellous bone grafts. Orthop Clin North Am 18:179-185

29. An YH, Friedman RJ (1999) Animal models in orthopedic research. CRC Press Inc., Boca Raton

30. Chalmers J, Gray DH, Rush J (1975) Observations on the induction of bone in soft tissues. J Bone Joint Surg Br 57:36-45

31. Dahners LE, Jacobs RR (1985) Long bone defects treated with demineralized bone. South Med J 78:933-934
32. Einhorn TA, Lane JM, Burstein AH, Kopman CR, Vigorita VJ (1984) The healing of segmental bone defects induced by demineralized bone matrix: a radiographic and biomechanical study. J Bone Joint Surg Am 66:274-279

33. Gepstein R, Weiss RE, Saba K, Hallel T (1987) Bridging large defects in bone by demineralized bone matrix in the form of a powder. J Bone Joint Surg Am 69:984-992

34. Hulth A, Johnell O, Henricson A (1988) The implantation of demineralized fracture matrix yields more new bone formation than does intact matrix. Clin Orthop 234:235-249

35. Lindholm TS, Ragni P, Lindholm TC (1988) Response of bone marrow stroma cells to demineralized cortical bone matrix in experimental spinal fusion in rabbits. Clin Orthop 230:296-302

36. Tuli SM, Singh AD (1978) The osteoinductive property of decalcified bone matrix: an experimental study. J Bone Joint Surg $\mathrm{Br}$ 60:116-123

37. Urist MR (1965) Bone: formation by autoinduction. Science 150:893-899

38. Urist MR, Silverman BF, Buring K, Dubuc FL, Rosenberg JM (1967) The bone induction principle. Clin Orthop 53:243-283

39. Burwell RG (1985) The function of bone marrow in the incorporation of a bone graft. Clin Orthop 200:125-141

40. Martin G, Boden SD, Morone MA, Titus L (1999) New formulations of demineralized bone matrix as a more effective graft alternative in experimental posterolateral lumbar spine arthrodesis. Spine 24:637-645

41. Urist MR, Mikulski AJ, Lietz A (1979) Solubilized and insolubilized bone morphogenetic protein. Proc Natl Acad Sci USA 76:1928-1832

42. Urist MF, Sato K, Brownell AG (1983) Human bone morphogenetic protein. Proc Soc Exp Biol Med 173:194-199

43. Bauer TW, Muschler GF (2000) Bone graft materials: an overview of the basic science. Clin Orthop Relat Res 371:10-27

44. Khan SN, Cammisa FPJ, Sandhu HS, Diwan AD, Girardi FP, Lane JM (2005) The biology of bone grafting. J Am Acad Orthop Surg 13:77-86

45. Guizzardi S, Di Silvestre M, Scandroglio R, Ruggeri A, Savini R (1992) Implants of heterologous demineralized bone matrix for induction of posterior spinal fusion in rats. Spine 17:701-707

46. Goldberg VM, Stevenson S, Shaffer JW, Davy D, Klein L, Zika J, Field G (1990) Biological and physical properties of autogenous vascularized fibular grafts in dogs. J Bone Joint Surg Am 72:801810

47. Boden SD, Schimandle JH, Hutton WC (1995) Lumbar intertransverse process spine arthrodesis using a bovine-derived osteoinductive bone protein. J Bone Joint Surg Am 77:1404-1417

48. Boden SD, Schimandle JH, Hutton WC (1995) 1995 Volvo award in basic sciences. The use of an osteoinductive growth factor for lumbar spinal fusion II. Study of dose, carrier, and species. Spine 20:2633-2644

49. Boden SD, Schimandle JH, Hutton WC (1995) An experimental lumbar intertransverse process spinal fusion model: radiographic, histologic, and biomechanical healing characteristics. Spine 20:412-420

50. Silcox DH, Boden SD, Schimandle JH, Johnson P, Whitesides TE, Hutton WC (1998) Reversing the inhibitory effect of nicotine on spinal fusion using an osteoinductive protein extract. Spine 23:291-296

51. Morone MA, Boden SD (1998) Experimental posterolateral lumbar spinal fusion with a demineralized bone matrix gel. Spine 23:159-167 